\title{
Sleep duration in elderly obese patients correlated negatively with intake fatty
}

\author{
Aline Alves Santana', Gustavo Duarte Pimentel ${ }^{2}$, Monica Romualdo ${ }^{3}$, Lila Missae Oyama', \\ Ronaldo Vagner Thomatieli Santos ${ }^{4}$, Ricardo Aurino Pinho ${ }^{5}$, Claudio Teodoro de Souza ${ }^{5}$, Bruno Rodrigues ${ }^{6,7}$, \\ Erico Chagas Caperuto ${ }^{6}$ and Fabio Santos Lira ${ }^{5^{*}}$
}

\begin{abstract}
Study objectives: The purpose of the present study was to evaluate the relationship between sleep duration and dietary habits in elderly obese patients treated at an institute of cardiology.

Methods: The fifty-eight volunteers were elderly patients with obesity (classified as obese according to BMI) of both genders, between 60 and 80 years of age. All participants were subjected to assessments of food intake, anthropometry, level of physical activity, and duration of sleep.

Results: The men had significantly greater weight, height, and waist circumference than women. Sleep durations were correlated with dietary nutrient compositions only in men. We found a negative association between short sleep and protein intake $(r=-0.43 ; p=0.02)$, short sleep and monounsaturated fatty acids intake $(r=-0.40 ; p=0.03)$, and short sleep and cholesterol dietary intake $(r=-0.50 ; p=0.01)$.

Conclusions: We conclude that mainly in men, volunteers that had short sleep duration showed a preference for high energy-density as fatty food, at least in part, may explain the relationship between short sleep duration and the development of metabolic abnormalities.
\end{abstract}

Keywords: Obesity, Sleep, Food intake, Elderly

\section{Introduction}

In human subjects, studies have pointed to the possible involvement of altered sleep hours in the altered energy balance of the body and to alterations in the sleep pattern as a contributory factor to increased obesity [1-3].

Epidemiological and laboratory studies have indicated that self-reported short sleep duration is associated with increased risks for metabolic disruption, including impaired glucose tolerance, impaired insulin resistance, increased ghrelin, decreased leptin, and increased body mass index (BMI) $[1,4]$. These findings may partially explain the increased mortality associated with short sleep duration, which has been replicated by many studies $[5,6]$. But the role of diet in these sleep-related metabolic phenomena is currently unknown.

\footnotetext{
* Correspondence: fabioslira@gmail.com

${ }^{5}$ Laboratório de Fisiologia e Bioquímica do Exercício, Universidade do Extremo Sul Catarinense, Criciúma, SC, Brazil

Full list of author information is available at the end of the article
}

A higher energy intake has been reported in 3-day totally sleep deprived adults [7]. Moreover, early research has suggested a preference for high-fat foods in sleepdeprived humans, [7,8] and recent research in men sleeping $4 \mathrm{~h}$ each night for two consecutive nights found that the men had an increased appetite, especially for energy-dense foods with high-carbohydrate contents [4].

Spiegel et al. [9] showed that the appetite for energyrich nutrients with high carbohydrate content, including sweets, salty snacks, and starchy foods, increased by 33$45 \%$; by contrast, the appetite for fruits, vegetables, and high-protein nutrients was less affected.

Lennernas et al. [10] observed a strong preference for the intake of "fast food" and energy-rich snacks during the nocturnal working hours in night workers. The preference for such foods is a source of great concern since, in addition to presenting a hormone pattern that predisposes subjects to an increased energy intake [9] individuals with sleep loss (common in night workers) tend to meet this need with foods of low nutritional quality 
[11-15]. This altered food intake can result from inadequate eating facilities during the night shift but, whatever its cause, it increases the risk of obesity [16] dyslipidaemias, [17] and cardiovascular disease [11-15].

In 2002, a large-scale survey was conducted in several countries, including Brazil, with the aim of raising public awareness of the importance of sleep for health, productivity, and safety [18]. In that worldwide investigation, Brazil was classified as the country with the highest prevalence of symptoms associated with sleep disturbances.

Therefore, the purpose of the present study was to evaluate the relationship between sleep duration and dietary habits in elderly obese patients treated at an institute of cardiology.

\section{Methods}

\section{Sample}

This cross-sectional epidemiological study was conducted at the Institute of Cardiology in São Paulo. To be recruited, volunteers had be patient at the Institute of Cardiology, agree to participate in the study; agree to sign the Instrument of Consent; be classified as obese according to BMI (BMI of 30.0 to $39.9 \mathrm{~kg} / \mathrm{m}^{2}$ ), be between 60 and 80 years of age, being in full cognitive and mental condition; not having hearing impairment. Patients on medications such as immunosuppressants, antidepressants, or corticosteroids; and patients with polycystic ovary syndrome, cushing syndrome, hypothyroidism, chronic renal failure syndrome, obstructive sleep apnea, asthma, or depression were excluded.

Fifty-eight volunteers' elderly (twenty men and thirtyeight women) composed the sample. Twenty-six women volunteers were following dietary, as well as twelve men volunteers were also on dietary treatment. All patients had heart disease, while $45 \%$ had hypertension, $38 \%$ had diabetes mellitus type II, $69 \%$ had dyslipidemias, 3\% had stroke, $2 \%$ had carotid artery disease, gastritis, arthrosis, bronchitis, heart failure, nephrolithiasis, typical chest pain, and arrhythmia, 10\% had impaired fasting glucose, $5 \%$ had glucose intolerance, $3 \%$ had atrial fibrillation and chronic obstructive pulmonary disease, and 5\% had metabolic syndrome and ischemic cardiomyopathy. Full written consent was obtained from all patients and the protocol was approved by both the Institute of Cardiology Committee (4132/2011), and the Federal University of São Paulo Committee (1826/11). Additionally, the protocol is described on the Brazilian Platform for Experimental Research with Human Beings.

\section{Food intake evaluation}

Food intake was determined through Dietary Recall Usual, in which volunteers recall their food intake routinely. The dietary profiles were analyzed using Avanutri ${ }^{\circledR}$ Software.

\section{Anthropometric evaluation}

The anthropometric measures (weight, height, waist circumference, and calculation of body mass index) were assessed from the medical record. A stadiometer installed on the balance was used for the measurement of height. To check weights, a Filizola digital scale with a maximum capacity of 150 kilograms with accuracy of $50 \mathrm{~g}$ was used. The waist circumference was measured at the midpoint between the iliac crest and last rib with inelastic tape. BMI was calculated by dividing body weight (in $\mathrm{kg}$ ) by height (in meters) of the square, according to formula $\left(\mathrm{BMI}=\right.$ body weight $/$ height $\left.^{2}\right)$. All measurements were performed according to the recommended techniques.

\section{Physical activity evaluation}

To evaluate the degree of physical activity, the questionnaire used was the International Physical Activity Questionnaire (IPAQ). The questions are related to time spent doing physical activity in the previous week. Activities included were: the performing at work, going from one place to another, leisure activities including sport and exercise, or activities at home or in the garden.

\section{Evaluation of sleep time}

Evaluation of sleep time was determined by a questionnaire about nocturnal sleep duration in hours.

\section{Statistical analysis}

Implementation of the Kolmogorov-Smirnov test revealed that the results of experiments were distributed normally. Thus, the variables were expressed by descriptive analysis (mean and standard deviation), and the Pearson correlation was used to examine the associations between sleep duration and food intake (energy, protein, monounsaturated fatty acids, and cholesterol dietary).

The level of statistical significance used was 5\% in all tests. For all analyses, we used software STATISTICA version 6.0.

\section{Results}

Fifty-eight volunteers completed all measurements. The characteristics of the participants are presented in Table 1. Male subjects were $65.0 \pm 3.7$ years of age, and the women were $66.9 \pm 4.2$ years of age. The mean height and weight for man were $1.68 \pm 0.07 \mathrm{~m}$ and $95.9 \pm 12.5 \mathrm{~kg}$, respectively; in women, they were $1.55 \pm 0.06 \mathrm{~m}$ and $82.4 \pm 9.5$, respectively. The mean BMI for men was $33.7 \pm 2.8 \mathrm{~kg} / \mathrm{m}^{2}$, and for the women, it was $33.9 \pm 2.6 \mathrm{~kg} / \mathrm{m}^{2}$. The mean waist circumference of the 
Table 1 Parameters anthropometric, physical activity, sleep and dietetic of elderly subjects $(n=58)$

\begin{tabular}{|c|c|c|c|}
\hline \multirow[t]{2}{*}{ Parameters } & Mean \pm SD & Mean \pm SD & \multirow[t]{2}{*}{ Test $t$ ( $p$ value } \\
\hline & $\operatorname{Man}(n=20)$ & Female $(n=38)$ & \\
\hline Age (y) & $65.0 \pm 3.7$ & $66.9 \pm 4.2$ & $0.00^{*}$ \\
\hline Weight (kg) & $95.9 \pm 12.5$ & $82.4 \pm 9.5$ & $0.00 *$ \\
\hline Height (m) & $1.68 \pm 0.07$ & $1.55 \pm 0.06$ & $0.00^{*}$ \\
\hline $\mathrm{BMI}\left(\mathrm{kg} / \mathrm{m}^{2}\right)$ & $33.7 \pm 2.8$ & $33.9 \pm 2.6$ & 0.38 \\
\hline Waist circumference $(\mathrm{cm})$ & $115.5 \pm 8.0$ & $108.7 \pm 7.1$ & $0.00^{*}$ \\
\hline IPAC & $2.3 \pm 1.6$ & $2.5 \pm 1.0$ & 0.27 \\
\hline Sleep duration (h) & $6.8 \pm 1.5$ & $6.5 \pm 1.70$ & 0.25 \\
\hline Energy caloric (kcal) & $1433.5 \pm 472.5$ & $1200.0 \pm 388.8$ & $0.03^{*}$ \\
\hline $\mathrm{CHO}(\mathrm{g})$ & $183.8 \pm 53.5$ & $162.0 \pm 62.6$ & 0.08 \\
\hline Protein $(\mathrm{g})$ & $77.2 \pm 27.5$ & $63.0 \pm 30.1$ & $0.03^{*}$ \\
\hline Total lipids (g) & $43.3 \pm 28.1$ & $33.1 \pm 16.6$ & 0.07 \\
\hline Saturated fatty acids (\%) & $12.1 \pm 8.35$ & $9.38 \pm 5.8$ & 0.10 \\
\hline Monounsaturated fatty acids (\%) & $11.0 \pm 8.3$ & $7.4 \pm 5.0$ & $0.04 *$ \\
\hline Polyunsaturated fatty acids (\%) & $4.7 \pm 2.9$ & $4.9 \pm 5.1$ & 0.44 \\
\hline Dietary cholesterol (mg) & $158.5 \pm 79.0$ & $155.5 \pm 93.7$ & 0.45 \\
\hline
\end{tabular}

men was $115.5 \pm 8.0 \mathrm{~cm}$, and for the women, it was $108.7 \pm 7.1 \mathrm{~cm}$. The mean nocturnal sleep duration for the men was $6.8 \pm 1.5$ hours, and for women, it was $6.5 \pm 1.70$ hours. The mean number of kilocalories consumed was $1433.5 \pm 472.5$ for men and $1200.0 \pm 388$ for women.

A correlation between sleep duration and nutrient intake was found only in the men and are displayed Figure 1. A negative correlation was found between sleep duration and energy intake for men $(r=-0.28 ; \mathrm{p}=0.11)$, sleep duration and protein intake $(\mathrm{r}=-0.43 ; \mathrm{p}=0.02)$, sleep duration and monounsaturated fatty acids intake for men $(r=-0.40 ; p=0.03)$ and for women $(r=0.05$; $\mathrm{p}=0.72$ ), and sleep duration and cholesterol dietary intake for men $(\mathrm{r}=-0.50 ; \mathrm{p}=0.01)$ and for women $(\mathrm{r}=0.28 ; \mathrm{p}=0.08)$. The men had significantly greater weights $(14 \%, \mathrm{p}=0.00001)$, heights $(8 \%, \mathrm{p}=0.0001)$, waist circumferences $(6 \%, \mathrm{p}=0.001)$, and caloric $(12 \%$, $\mathrm{p}=0.03)$, protein $(22 \%, \mathrm{p}=0.03)$, and monounsaturated fatty acids intake $(49 \%, \mathrm{p}=0.04)$ than women (Table 1$)$.
A
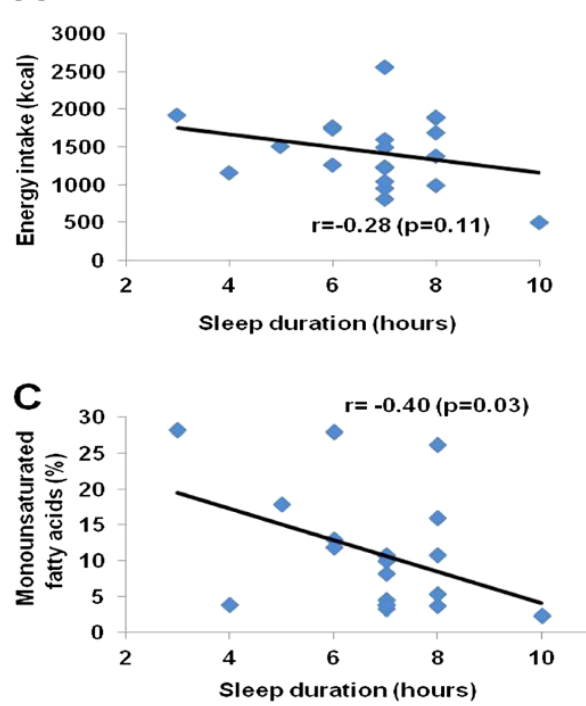

B

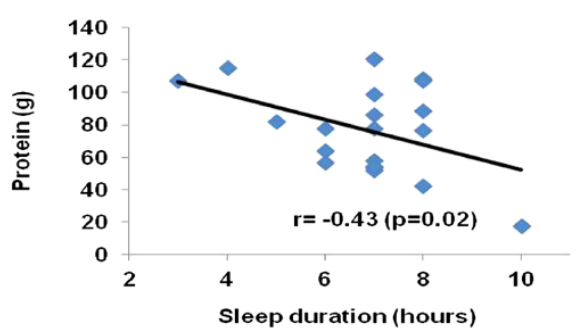

D

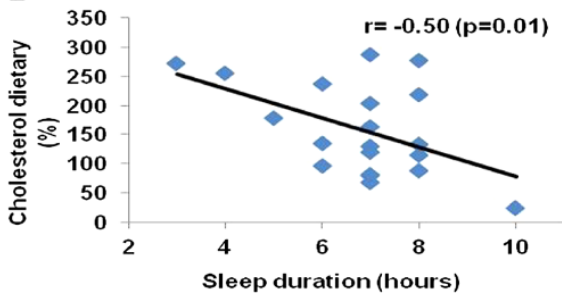

Figure 1 The correlation between dietary and sleep duration in men. 


\section{Discussion}

In the present study, we found links between short sleep duration and increases in energy intake and nutritional consumption of protein and cholesterol. These associations were significant in elderly men but not in elderly women. Here, we examined the impact of diet by usual dietary recall to demonstrate an association between short sleep duration and food consumption and specific nutrients such as dietary cholesterol, protein, monounsaturated fatty acids, and energy intake.

The energy intake in men and women reported implausibly low intakes. A possible explanation may be an underreporting of dietary intake by obese subjects, and also this low energy can be justified, since some voluntary were following dietary.

Numerous studies have documented a high prevalence of underreported energy intakes from-24 hours recalls, food records, and food- frequency questionnaire [19-21].

Underreporting varied according to the dietary assessment method used, but also by the composition of samples from subjects with obesity. Many researchers found that obese people are more prone to underreporting [22]. The few studies on underreporting conducted in developing countries were reviewed and it was found that the proportion of underreporters varied largely from one study and country to another [23].

This hypothesis was confirmed by Scagliusi et al., [24] that underreporting is a prevalent in dietary assessment in a sample of Brazilian women. In another study [25] with subjects as overweight and obesity residing in and around Spanish Town, Jamaica, only about half of the men and the women reported energy intakes within the limits defined as plausible. More than a third of women and nearly a quarter of men reported low intakes. Thus, the underreporting isn't associated only with dietary assessment method used and composition of samples, but still with country of study.

As reported in other studies, short sleepers have a higher energy intake, suggesting that short sleepers may be more susceptible to weight gain and obesity. The associations found could be explained by appetite hormones, with elevations in serum ghrelin and reductions in serum leptin being partially responsible for the increase in subjective appetite $[5,26]$. A number of causal pathways linking short sleep duration with obesity have been suggested based on experimental studies of sleep deprivation. One mechanism by which sleep deprivation might predispose subjects to weight gain is by increasing caloric intake. Total sleep deprivation experiments in animals have consistently found that sleep deprivation produces hyperphagia [27]. Partial sleep deprivation experiments in humans suggest a similar effect [28]. Two epidemiologic studies have demonstrated that short sleepers have reduced levels of leptin and elevated levels of ghrelin, supporting the effect of short sleep durations on appetite regulation $[5,26]$.

Additional studies have shown that, more important than an increase in total caloric intake, the proportional intake of specific macronutrients such as carbohydrates or fat [29] as cholesterol, trans-fats and saturated fats could have increased [9].

As expected, analyses of usual dietary recall confirmed the increased preferences for eating energy-dense foods, such as cholesterol-rich foods. Nishiura et al. [30] examined the impact of diet by including questions on dietary patterns, which have been reported to better reflect the association between dietary habit and obesity; [31-33] as expected, self-reporting a preference for fatty food successfully predicted the incidence of obesity, and the preference for fatty food was significantly associated with sleep duration [30].

There is some evidence based on the association between serum cholesterol and saturated fatty acids associated with obesity and metabolic syndrome, which are major risk factors for cardiovascular disease. Study by Waqar et al., [34] demonstrated that the consumption of a normal calorie high-fat diet can lead to insulin resistance and high blood pressure in rabbits, hallmarks of metabolic syndrome, and the consumption of $10 \%$ highfat diet enriched in cholesterol, induced much adverse effects, suggesting that the amount of fat consumed in a diet plays an important role in metabolic disorders and more susceptible to cholesterol-induced metabolic changes : pronounced systemic inflammation, marked elevation of plasma glucose, free fatty acids and insulin, and prominent accumulation of adipose tissue and also demonstrated that the intake of saturated fat with a normal number of calories is detrimental to glucose and lipid metabolism and induces disorders like metabolic syndrome.

It was found in the Seven Countries Study by Ancel Keys [35], the relationship between saturated fatty acids and serum cholesterol that was demonstrated in short[36] and long-term feeding trials [37,38]; however, a recent meta-analysis of prospective cohort studies showed that the intake of saturated fatty acids is not associated with an increased risk of coronary heart disease, stroke, or the two combined, before [39] or after [40] adjustment or serum total cholesterol. However, in patients who already have cardiovascular diseases, as the patients in this study, the suggestion is that the consumption is within the recommended values.

In present study, $69 \%$ of the subjects had exhibited dyslipidemia. Saturated fat and cholesterol intake in men and women surpassed the values currently recommended for this disease, and men may be considered most vulnerable to impairment by cardiovascular disease, since the dietary intake of total lipids, saturated 
fatty acids, and dietary cholesterol exceeded the dietary intake of women. It is known that dietary recommendations advise the reduction of saturated fat and cholesterol intake for cardiovascular disease risk reduction, with similar recommendations for the treatment of dyslipidemia.

The stronger relationship found between protein intake and dietary cholesterol could be partially justified because both are derived from food of animal origin, which are rich in protein and cholesterol, as well as saturated fatty acids. We suggest that the greater food intake of men with respect to protein was equivalent to their body composition, since men in this study had significantly greater weights, heights, and waist circumferences. Certainly, food consumption is related to food preferences by gender differences.

Although there is a substantial body of evidence that has shown the cardioprotective effects of diets high in MUFA, paradoxical results from experiments in monkeys show that a diet high in MUFA causes atherosclerosis equivalent to that observed in animals fed a diet high in SFA [41]. This effect appears to result from the increased secretion of cholesteryl oleate-enriched lipoproteins. These results, which are counter to the evidence that shows that MUFAs have beneficial effects, need to be further evaluated to determine whether they are relevant to humans. There is also evidence that a fat load provided by olive oil (versus fats high in either SFA or PUFA) increases the plasma levels of chylomicron remnants $[42,43]$ which are atherogenic lipoproteins. However, the preponderance of evidence indicates that dietary MUFAs have favorable effects on CHD risk [44]. However, it is known that the use of such fat provides benefits to patients with cardiac disease and possibly to obese individuals but requires discussions about the high consumption to promote the same benefits as may be associated with a shorter duration of sleep and its complications.

In conclusion, our transversal analysis showed that a preference for fatty food, protein, and monounsaturated fatty acids, at least in part, explains the effects of short sleep duration on the incidence of obesity and cardiovascular diseases, such as dyslipidemia. This study has additional limitations that require discussion. Nevertheless, this result enriches our knowledge of the feeding habits of obese elderly subjects, since this food consumption may favor the onset of co-morbidities associated with short sleep duration and obesity. But without doubt, these findings also motivate us to promote nutrition education and guidance on the importance of quality and duration of sleep and its relationship to health.

\section{Competing interests}

The authors declared no conflict of interest.

\section{Authors' contributions}

AAS, GDP, MR, LMO, RVTS, RAP, CTS, ECC, BR and FSL participated or helped carry out design of the study, sample collected, assess samples, performed the statistical analysis, and writing and discussion of paper. All authors read and approved the final manuscript.

\section{Acknowledgments}

Institute of Cardiology Dante Pazzanese, especially outpatient nutrition team, which allowed the work to be done.

\section{Author details}

${ }^{1}$ Departamento de Fisiologia, Disciplina de Fisiologia da Nutrição, Universidade Federal de São Paulo-EPM, São Paulo, Brazil. ${ }^{2}$ Departamento de Medicina Interna, Universidade Estadual de Campinas, São Paulo, Brazil. ${ }^{3}$ Instituto Dante Pazzanese de Cardiologia, São Paulo, Brazil. " Departamento de Biociências, Campus Baixada Santista, Universidade Federal de São Paulo, São Paulo, Brazil. 'Laboratório de Fisiologia e Bioquímica do Exercício, Universidade do Extremo Sul Catarinense, Criciúma, SC, Brazil. ${ }^{6}$ Human Moviment Laboratory, São Judas Tadeu University, São Paul, Brazil.

${ }^{7}$ Hypertension Unit, Heart Institute (InCor), Medical School of University of São Paulo, São Paulo, Brazil.

Received: 1 June 2012 Accepted: 24 July 2012

Published: 7 August 2012

\section{References}

1. Spiegel K, Knutson K, Leproult R, Tasali E, Van Cauter E: Sleep loss: a nove risk factor for insulin resistance and type 2 diabetes. J Appl Physiol 2005, 99:2008-2010.

2. Svatikova A, Wolk R, Gami AS, Pohanka M, Somers VK: Interactions between obstructive sleep apnea and the metabolic syndrome. Curr Diab Rep 2005, 5:53-58.

3. Flier JS, Elmquist JK: A good night's sleep: future antidote to the obesity epidemic? Ann Intern Med 2004, 141:885-886.

4. Cummings DE, Foster KE: Ghrelin-leptin tango in body-weight regulation. Gastroenterology 2003, 124:1532-1535.

5. Taheri S, Lin L, Austin D, Young T, Mignot E: Short sleep duration is associated with reduced leptin, elevated ghrelin, and increased body mass index. PLoS Med 2004, 1:e62.

6. Pejovic E, Vgontzas AN, Basta M, Tsaoussoglou M, Zoumakis E, Vgontzas A, Bixler EO, Chrousos GP: Leptin and hunger levels in young healthy adults after one night of sleep loss. J Sleep Res 2010, [Epub ahead of print].

7. Dinges DF, Chugh DK: Physiologic correlates of sleep deprivation. In Physiology, stress and malnutrition: functional correlates, nutritional intervention. Edited by Kinney JM, Tucker HN. New York: Lippincott-Raven; 1997:1-27.

8. Naitoh P: Sleep deprivation in human subjects: a reappraisal. Wak Sleep 1976, 1:53-60

9. Spiegel K, Tasali E, Penev P, Van Cauter E: Brief communication: sleep curtailment in healthy young men is associated with decreased leptin levels, elevated ghrelin levels, and increased hunger and appetite. Ann Intern Med 2004, 141:846-850.

10. Lennernas MAC, Akersted T, Hagman U, Bruce A, Hambraeus L: A new approach for evaluation of meal quality and meal patterns. J Hum Nutr Dietetics 1993, 6:261-273.

11. Armstrong S: A chronometric approach to the study of feeding behaviour. Neurosci Biobehav Rev 1980, 4:27-53.

12. Adams CE, Morgan KJ: Periodicity of eating: implications for human food consumption. Nutr Res 1981, 1:525-550

13. de Venne WP V-V, Westerterp KR: Influence of the feeding frequency on nutrient utilization in man: consequences for energy metabolism. Eur J Clin Nutr 1991, 45:161-169.

14. Moore JG: Biological Rhythms in Clinical and Laboratory Medicine. In Chronobiology of the gastrointestinal system. Edited by Touitou Y, Haus E. Berlin: Springer; 1992:410-417. Berlin: Springer-Verlag.

15. Sudo N, Ohtsuka R: Nutrient intake among female shift workers in a computer factory in Japan. Int J Food Sci Nutr 2001, 52:367-378.

16. van Amelsvoort LG, Schouten EG, Kok FJ: Duration of shiftwork related to body mass index and waist to hip ratio. Int J Obes Relat Metab Disord 1999, 23:973-978. 
17. Romon M, Nuttens MC, Fievet C, Pot P, Bard JM, Furon D, Fruchart JC: Increased triglyceride levels in shift workers. Am J Med 1992, 93:259-262

18. Soldatos CR, Allaert FA, Ohta T, Dikeos DG: How do individuals sleep around the world? Results from a single-day survey in ten countries. Sleep Med 2005, 6:5-1.

19. Heitmann BL, Lissner L: Dietary underreporting by obese individuals-is it specific or non-specific? BMJ 1995, 311(7011):986-989.

20. Goris AH, Westerterp-Plantenga MS, Westerterp KR: Undereating and underrecording of habitual food intake in obese men: selective underreporting of fat intake. Am J Clin Nutr 2000, 71(1):130-134.

21. Krebs-Smith SM, Graubard BI, Kahle LL, Subar AF, Cleveland LE, BallardBarbash R: Low energy reporters vs others: a comparison of reported food intakes. Eur J Clin Nutr 2000, 54(4):281-287.

22. Bazelmans C, Matthys C, De Henauw S, Dramaix M, Kornitzer M, De Backer $G$, Levêque A: Predictors of misreporting in an elderly population: the 'Quality of life after 65' study. Public Health Nutr 2007, 10(2):185-191.

23. Scagliusi FB, Ferriolli $E$, Lancha AH Jr: Underreporting of energy intake in developing nations. Nutr Rev 2006, 64(7 Pt 1):319-330.

24. Scagliusi FB, Ferriolli E, Pfrimer K, Laureano C, Cunha CS, Gualano B, Lourenço BH, Lancha AH Jr: Underreporting of energy intake in Brazilian women varies according to dietary assessment: a cross-sectional study using doubly labeled water. J Am Diet Assoc 2008, 108(12):2031-2040.

25. Mendez MA, Wynter S, Wilks R, Forrester T: Under- and overreporting of energy is related to obesity, lifestyle factors and food group intakes in Jamaican adults. Public Health Nutr 2004, 7(1):9-19.

26. Chaput JP, Després JP, Bouchard C, Trembblay A: Short sleep duration is associated with reduced leptin levels and increased adiposity: results from the Québec Family Study. Obesity 2007, 15:253-261.

27. Rechtschaffen A, Bergmann BM: Sleep deprivation in the rat by the diskover-water method. Behav Brain Res 1995, 69:55-63.

28. Patel SR, Hu FB: Short sleep duration and weight gain: a systematic review. Obesity 2008, 16:643-653.

29. Wells JC, Siervo M: Obesity and energy balance: is the tail wagging the dog ? Eur J Clin Nutr 2011, 65:1173-1189.

30. Nishiura C, Noguchi J, Hashimoto H: Dietary Patterns only partially explain the effect of short sleep duration on the incidence of obesity. Sleep 2010, 33:753-757.

31. Torres SJ, Nowson CA: Relationship between stress, eating behavior, and obesity. Nutrition 2007, 23:887-894.

32. Rissanen A, Hakala P, Lissner L, et al: Acquired preference especially for dietary fat and obesity: a study of weight-discordant monzygotic twin pairs. Int J Obesit Relat Metab Disord 2002, 26:973-977.

33. Binkley JK, Eales J, Jekanowski M: The relation between dietary change adn rising US obesity. Int J Obes Relat Metab Disord 2000, 24:1032-1039.

34. Waqar AB, Koike T, Yu Y, Inoue T, Aoki T, Liu E, Fan J: High-fat diet without excess calories induces metabolic disorders and enhances atherosclerosis in rabbits. Atherosclerosis 2010, 213(1):148-155.

35. Keys AB: Seven Countries: a multivariate analysis of death and coronary heart disease. London, England. Cambridge Massachusetts: Harvard University Press; 1980.

36. Mensik RP, Zock PL, Kester AD, et al: Effects of dietary fatty acids and carbohydrates on the ratio of serum total to HDL cholesterol and on serum lipids and apolipoproteins: a meta-analysis of 60 controlled trials. Am J Clin Nutr 2003, 77:1146-1155.

37. Clarke R, Frost C, Collins R, et al: Dietary lipids and blood cholesterol: quantitative meta-analysis of metabolic ward studies. BMJ 1997, 314:112117 .

38. Frantz ID Jr, Dawson EA, Ashman PL, et al: Test of effect of lipid lowering by diet on cardiovascular risk. The Minnesota Coronary Survey. Arteriosclerosis 1989, 9:129-135.

39. Siri-Tarino PW, Sun Q, Hu FB, et al: Meta-analysis of prospective cohort studies evaluating the association of saturated fat with cardiovascula disease. Am J Clin Nutr 2010, 91:535-546.

40. Scarborough P, Rayner M, van Dis I, et al: Meta-analysis of effect of saturated fat intake on cardiovascular disease: overadjustment obscures true associations. Am J Clin Nutr 2010, 92:458-459.

41. Rudel LL, Parks JS, Sawyer JK: Compared with dietary monounsaturated and saturated fat, polyunsaturated fat protects African green monkeys from coronary artery atherosclerosis. Arterioscler Thromb 1995, 15:21012110
42. de Bruin TW, Brouwer CB: van Linde-Sibenius Trip M, Jansen H. Erkelens DW. Different postprandial metabolism of olive oil and soybean oil: a possible mechanism of the high-density lipoprotein conserving effect of olive oil. Am J Clin Nutr 1993, 58:477-483.

43. Higashi K, Ishikawa T, Shige H, Tomiyasu K, Yoshida H, Ito T, Nakajima K, Yonemura A, Sawada S, Nakamura H: Olive oil increases the magnitude of postprandial chylomicron remnants compared to milk fat and safflower oil. J Am Coil Nutr 1997, 16:429-434.

44. Kris-Etherton PM: Monounsaturated Fatty Acids and Risk of Cardiovascular Disease. Circulation 1999, 100:1253-1258.

doi:10.1186/1476-511X-11-99

Cite this article as: Santana et al:: Sleep duration in elderly obese patients correlated negatively with intake fatty. Lipids in Health and Disease 2012 11:99.

\section{Submit your next manuscript to BioMed Central and take full advantage of:}

- Convenient online submission

- Thorough peer review

- No space constraints or color figure charges

- Immediate publication on acceptance

- Inclusion in PubMed, CAS, Scopus and Google Scholar

- Research which is freely available for redistribution 